\title{
Effect of the combinations between pea proteins and soluble fibres on cholesterolaemia and cholesterol metabolism in rats
}

\author{
Cinzia Parolini, Stefano Manzini, Marco Busnelli, Elena Rigamonti, Marta Marchesi, Erika Diani, \\ Cesare R. Sirtori and Giulia Chiesa* \\ Department of Pharmacological Sciences, Università degli Studi di Milano, via Balzaretti 9, 20133 Milan, Italy
}

(Submitted 16 March 2012 - Final revision received 28 January 2013 - Accepted 28 January 2013 - First published online 5 March 2013)

\begin{abstract}
Many functional foods and dietary supplements have been reported to be beneficial for the management of dyslipidaemia, one of the major risk factors for CVD. Soluble fibres and legume proteins are known to be a safe and practical approach for cholesterol reduction. The present study aimed at investigating the hypocholesterolaemic effect of the combinations of these bioactive vegetable ingredients and their possible effects on the expression of genes regulating cholesterol homeostasis. A total of six groups of twelve rats each were fed, for $28 \mathrm{~d}$, Nath's hypercholesterolaemic diets, differing in protein and fibre sources, being, respectively, casein and cellulose (control), pea proteins and cellulose (pea), casein and oat fibres (oat), casein and apple pectin (pectin), pea proteins and oat fibres (pea + oat) and pea proteins and apple pectin (pea + pectin). Administration of each vegetable-containing diet was associated with lower total cholesterol concentrations compared with the control. The combinations (pea + oat and pea + pectin) were more efficacious than fibres alone in modulating cholesterolaemia $(-53$ and $-54 \%$, respectively, at $28 \mathrm{~d} ; P<0.005)$. In rats fed the diets containing oat fibres or apple pectin, alone or in combination with pea proteins, a lower hepatic cholesterol content $(P<0 \cdot 005)$ and higher hepatic mRNA concentrations of CYP7A1 and NTCP were found when compared with the control rats $(P<0 \cdot 05)$. In summary, the dietary combinations of pea proteins and oat fibres or apple pectin are extremely effective in lowering plasma cholesterol concentrations in rats and affect cellular cholesterol homeostasis by up-regulating genes involved in hepatic cholesterol turnover.
\end{abstract}

\section{Key words: Pea proteins: Soluble fibres: Cholesterol: Rats}

Dyslipidaemia is one of the major risk factors for CVD, the leading cause of death in Western populations and a constantly growing cause of morbidity and mortality worldwide $^{(1)}$. Lifestyle changes, one of which is diet, remain the cornerstone for the treatment of dyslipidaemia and the prevention of CVD. Lifestyle changes, in fact, may reduce the risk of premature CHD by $82 \%{ }^{(2)}$, whereas dietary changes alone may reduce the risk by $60 \%{ }^{(3,4)}$.

A large number of functional foods and dietary supplements have been reported to be beneficial for the management of dyslipidaemia ${ }^{(5,6)}$. Among those, dietary fibres are recommended as a safe and practical approach for cholesterol reduction. This activity is limited to some soluble fibres, whereas insoluble fibres do not exert this effect ${ }^{(7)}$. Soluble fibres known to lower LDL-cholesterol include pectins from apple and citrus fruits, $\beta$-glucan from oats and barley, and fibres from flaxseed and psyllium ${ }^{(8)}$. Based on meta-analyses showing their hypocholesterolaemic activity ${ }^{(9)}$, health claims exist for both oat $\beta$-glucan and barley $\beta$-glucans for cholesterol reduction ${ }^{(10,11)}$. The mechanisms behind this effect are not fully understood: bile acid binding has been suggested, but there are also other potential means for the reduction ${ }^{(12)}$.

Substitution of animal proteins with vegetable proteins appears to be associated with a lower risk of CHD. Soya protein consumption has been shown to successfully reduce cholesterolaemia in experimental animals, when increased by dietary means $^{(13,14)}$, as well as in human subjects with cholesterol elevations of genetic or non-genetic origin ${ }^{(15,16)}$. This hypocholesterolaemic effect is not limited to soya, but it appears to be a feature of most legume proteins. Indeed, a strong cholesterol reduction has been shown in animals fed proteins purified from lupin and pea seeds ${ }^{(17,18)}$.

A potentially effective strategy for cholesterol reduction through the diet is that of combining various cholesterollowering foods in one diet ${ }^{(6)}$. The present study attempted to evaluate, in a recognised rat model of hypercholesterolaemia, the efficacy of a combination of legume proteins and soluble fibres. Pea proteins were selected, together with $\beta$-glucan from oat and pectin from apples. Pea proteins appear to provide an attractive alternative to soya proteins in view of the wide

Abbreviations: ABCG5, ATP-binding cassette transporter G5; ABCG8, ATP-binding cassette transporter G8; CYP7A1, cholesterol 7 $\alpha$-hydroxylase. 
availability, low cost and appropriate taste for the non-oriental population ${ }^{(19)}$. Vegetable protein and fibres were administered with the diet, alone or in combination, to evaluate a possible additive or synergistic effect. Moreover, mechanisms behind the hypocholesterolaemic effect were explored through realtime quantitative PCR analyses.

\section{Methods}

\section{Animals, diets and experimental protocol}

Procedures involving animals and their care were conducted in accordance with the institutional guidelines that are in compliance with national (D.L. no. 116, G.U. Suppl. 40, 18 February 1992, Circolare no. 8, G.U. Luglio 1994) and international laws and policies (EEC Council Directive 86/609, OJL 358, 1, 12 December 1987; Guide for the Care and Use of Laboratory Animals published by the US National Institute of Health, NIH Publication no. 85-23, revised 1996). The experiments were supervised by the Laboratory Animal Welfare Service at our Department.

A total of seventy-two male Sprague-Dawley rats (body weight 200-225g; Charles River Italia) were housed in a room with controlled lighting $(12 \mathrm{~h} / \mathrm{d})$, constant temperature and relative humidity. During the first week, they were fed a commercial non-purified diet (Mucedola) and then divided into six groups of twelve rats on the basis of body weight so that the distribution between the groups was similar. The animals were then fed for $28 \mathrm{~d}$ ad libitum with Nath's ${ }^{(17)}$ hypercholesterolaemic diet (control group) or diets identical to Nath's diet except for the protein or fibre content. The composition of the experimental diets is shown in Table 1 . The protein content in each diet $(20 \%)$ was either the total protein isolate from Pisum sativum (Pisane ${ }^{\circledR}$ C9; Provital Industrie SA) or casein as the control protein. Pisane ${ }^{\circledR} \mathrm{C} 9$ was constituted by $90.8 \%$ pea proteins on DM and low amounts of fat $(1.2 \%)$ and fibre $(0.9 \%)$. About the fibre content, the relative amount of cellulose (control) and apple pectin fibre was 7.5\%. Apple pectin was a highly methoxylated, low-gelling, high-viscous pectin from apple peels (degree of esterification 68-78\%, Pectin Classic AU 201-USP; Herbstreith \& Fox KG). Pectin Classic AU-201-USP used had a Staudinger index (intrinsic viscosity, limiting viscosity number) of $500 \mathrm{~cm}^{3} / \mathrm{g}$ (Dr Hans-Ulrich
Endress, Herbstreith \& Fox, personal communication, 2012). Oat fibres were included in the diet as a component of a dietary product, Oatwell ${ }^{\circledR} 28 \%$, an oat bran rich in $\beta$-glucan with a high viscosity and a high molecular weight (CreaNutrition AG). Oatwell ${ }^{\circledR} 28 \%$ contains $28 \% \beta$-glucan and $46 \%$ of total fibre. The relative amount of Oatwell ${ }^{\circledR} 28 \%$ in the rat diet was $11.6 \%$, thus the total fibre content of the diet was $5.3 \%$ and the $\beta$ glucan content was $3.25 \%$. Considering the composition of Oatwell ${ }^{\circledR} 28 \%$, the diets containing this product were also balanced for minerals, fat and starch content (Table 1). During the feeding period, body weight and food intake were recorded.

\section{Sample collection}

Fasting blood samples were collected into tubes containing $0 \cdot 1 \%(\mathrm{w} / \mathrm{v})$ EDTA before and after 14 and $28 \mathrm{~d}$ of dietary treatments. Plasma was separated by centrifugation at $8000 \mathrm{rpm}$ for $10 \mathrm{~min}$ at $4^{\circ} \mathrm{C}$ and stored at $-20^{\circ} \mathrm{C}$ for lipid analysis. At the end of the dietary treatments ( $28 \mathrm{~d})$, rats were killed and the liver was excised and immediately snap-frozen in liquid $\mathrm{N}_{2}$ for subsequent RNA isolation and analysis.

\section{Plasma and liver lipid measurement}

Plasma total cholesterol, HDL-cholesterol and TAG concentrations were measured with standard enzymatic techniques using a Roche Diagnostics Cobas autoanalyser. HDL-cholesterol was measured after the precipitation of apoB-containing lipoproteins with polyethylene glycol $(20 \%, \mathrm{w} / \mathrm{v})$ in $0.2 \mathrm{M}$-glycine ( $\mathrm{pH} 10)$. This method has been extensively used for the measurement of HDL-cholesterol concentrations in mice ${ }^{(20-23)}$, and has been validated in our laboratory for HDL-cholesterol quantification in rats by comparison with results obtained by fast protein liquid chromatography separation of lipoprotein fractions $^{(18)}$. VLDL + LDL-cholesterol concentrations were calculated as the difference between the total cholesterol and HDL-cholesterol concentrations.

Lipids were extracted from the liver with a mixture of chloroform-methanol ${ }^{(24)}$; lipid extracts were dried and the lipids dissolved using Triton X-100. Hepatic cholesterol and TAG contents were quantified by enzymatic assays (ABX Diagnostics).

Table 1. Composition of the experimental diets

\begin{tabular}{|c|c|c|c|c|c|c|}
\hline Ingredients ( $\mathrm{g} / \mathrm{kg})$ & Control (Nath's diet) & Pea & Oat & Pectin & Pea + oat & Pea + pectin \\
\hline Casein & 200 & - & 200 & 200 & - & - \\
\hline Pea proteins & - & 200 & - & - & 200 & 200 \\
\hline DL-Methionine & 4 & 4 & 4 & 4 & 4 & 4 \\
\hline Hegsted mineral mix & 40 & 40 & 35 & 4.0 & 3.5 & 40 \\
\hline Coconut oil & 250 & 250 & 245 & 250 & 245 & 250 \\
\hline Sucrose & 385 & 385 & 385 & 385 & 385 & 385 \\
\hline Starch & 31 & 31 & - & 31 & - & 31 \\
\hline Cholesterol & 10 & 10 & 10 & 10 & 10 & 10 \\
\hline Cholic acid & 5 & 5 & 5 & 5 & 5 & 5 \\
\hline Vitamins & + & + & + & + & + & + \\
\hline Cellulose & 75 & 75 & - & - & - & - \\
\hline Pectin & - & - & - & 75 & - & 75 \\
\hline OatWell ${ }^{\circledR} 28 \%$ & - & - & 116 & - & 116 & - \\
\hline
\end{tabular}




\section{Real-time PCR analysis}

Total RNA was isolated from the rat liver using the NucleoSpin RNA extraction kit (Macherey-Nagel) according to the manufacturer's instructions. RNA concentration and purity were estimated from optical density at 260 and $280 \mathrm{~nm}$, respectively. Total RNA $(1 \mu \mathrm{g})$ was reverse transcribed with random hexamer primers and MultiScribe reverse transcriptase (Applied Biosystems) following the manufacturer's instructions. Complementary DNA were quantified by real-time detection PCR on an Applied Biosystems 7900 sequence detector using SYBR ${ }^{\circledR}$ Green I and specific primers indicated in Table 2. Real-time detection was performed in a volume of $25 \mu \mathrm{l}$ containing $100 \mathrm{nmol} / 1$ of each primer and an iTaq SYBR Green Supermix with ROX $2 \mathrm{X}$ as recommended by the manufacturer (Bio-Rad). Conditions were $95^{\circ} \mathrm{C}$ for $10 \mathrm{~min}$, followed by forty cycles of $30 \mathrm{~s}$ at $95^{\circ} \mathrm{C}, 30 \mathrm{~s}$ at $55^{\circ} \mathrm{C}$ and $30 \mathrm{~s}$ at $72^{\circ} \mathrm{C}$. A final melting curve guaranteed the authenticity of the target product. The housekeeping gene cyclophilin was used for normalisation. Fold changes were calculated with the $\Delta \Delta C_{\mathrm{t}}$ method. The mRNA concentration of cyclophilin was not influenced by the experimental conditions.

\section{Immunoblotting of cholesterol $7 \alpha$-hydroxylase in liver microsomes}

Microsomes were prepared from liver extracts as described previously $^{(25)}$. Briefly, liver tissues were homogenised in $0 \cdot 25 \mathrm{M}$-sucrose buffer $(0.25 \mathrm{M}$-sucrose, $20 \mathrm{~mm}$-Tris acetate $(\mathrm{pH}$ 7.4), 1 mм-EDTA, $2 \times$ protease cocktail inhibitor; Sigma) using an Ultra-Turrax T25, followed by centrifugation at $600 \mathrm{~g}$ for $10 \mathrm{~min}$. Supernatants were further centrifuged at $10000 \mathrm{~g}$ for $20 \mathrm{~min}$, and then subjected to a second centrifugation step at $100000 \mathrm{~g}$ for $30 \mathrm{~min}$ at $4^{\circ} \mathrm{C}$. Pellets were resuspended in $50 \mathrm{~mm}$-Tris acetate $(\mathrm{pH} 7 \cdot 4), 1 \mathrm{~mm}$-EDTA and $20 \%$ (v/v) glycerol. For immunoblotting, $100 \mu \mathrm{g}$ of proteins were fractionated by SDS-PAGE in $12 \%$ acrylamide gels and then transferred onto a nitrocellulose membrane (GE Healthcare). A rabbit polyclonal antibody recognising mouse and rat cholesterol $7 \alpha$-hydroxylase (CYP7A1) (kindly provided by Dr David Russell, University of Texas Southwestern Medical Center, Dallas, USA) was used for overnight hybridisation at $4^{\circ} \mathrm{C}$, at a dilution of $1: 200$. The membrane was further incubated with horseradish peroxidase-conjugated anti-rabbit
IgG (Cell Signaling) at a dilution of 1:5000. The signal was detected with the Pierce ECL Western Blotting Substrate (Thermo Scientific). Membranes were then stripped at $42^{\circ} \mathrm{C}$ for $45 \mathrm{~min}$ in $62.5 \mathrm{~mm}$-Tris (pH 6.8), $2 \%$ SDS and $0.07 \%$ 2-mercaptoethanol, and reprobed with a rabbit polyclonal anti-Ig heavy chain-binding protein antibody (Cell Signaling) at a dilution of 1:1000. Membranes were further incubated with the secondary antibody and the signal was detected as described above. CYP7A1 and Ig heavy chain-binding protein signals were quantified with the ImageJ 1.46 program and CYP7A1 expression was normalised to Ig heavy chain-binding protein.

\section{Statistical analysis}

Data are expressed as mean values and standard deviations. Group differences were tested for statistical significance by multivariate ANOVA (repeated measures), followed by Tukey's post hoc test. $P<0.05$ was considered as statistically significant. Statistical analysis was performed using SYSTAT software (version 13; Systat Software, Inc.).

\section{Results}

\section{Effect of the diets on lipid concentrations in plasma} and liver

The vegetable proteins and fibres affected the body weight of the animals differently on the high-cholesterol regimen, when monitored during the $28 \mathrm{~d}$ of dietary treatment. The animals fed pea proteins and pea proteins + oat fibres grew significantly more than the control animals (mean weights at $28 \mathrm{~d}$ of the diet: 388.92 (SD 23.92) g in controls, 441.83 (SD 26.44) g in pea protein-fed rats and $442.92(\mathrm{SD} 27.78) \mathrm{g}$ in pea protein + oat fibre-fed rats, $P<0.005)$. This higher increase in body weight was consequent to a higher food intake (daily food intake: $18.26(\mathrm{SD} 1.45) \mathrm{g} / \mathrm{d}$ in controls, 22.29 (SD 3.63) g in pea protein-fed rats and 22.58 (SD 2.82) $\mathrm{g}$ in pea protein + oat fibre-fed rats, $P<0 \cdot 005$ ).

Each dietary regimen containing vegetable proteins and/or fibres led to lower total cholesterol concentrations when compared with the controls at both 14 and $28 \mathrm{~d}$ of the hypercholesterolaemic diet (Fig. 1(a)). The two combinations (pea proteins + oat fibres and pea proteins + apple pectin) proved more effective than fibres alone in modulating cholesterolaemia

Table 2. Sequences of the primers used for real-time PCR analysis

\begin{tabular}{lll}
\hline Genes & Forward primer (from $5^{\prime}$ to $3^{\prime}$ ) & Reverse primer (from $5^{\prime}$ to $3^{\prime}$ ) \\
\hline ABCG5 & TGGACTGCATGACTGCAAAT & GAACACCAACTCTCCGTAAG \\
ABCG8 & GCTCAGTTCAAGTTACCGTG & CTGCCTGTGATAACGTCGAG \\
BSEP & TCTATGGACTCTGCTTTGCCTTTT & GCCCAGACCTTCGTAGGCTA \\
Cyclophilin & AGCACTGGGGAGAAAGGATT & AGCCACTCAGTCTTGGCAGT \\
HMG 1 CAA reductase & CACCATTCCTGCAACCTTTT & GTACCGGCAGGTCATTCAGT \\
LDL receptor & CCCAGCCTACAAACTGGAAA & CCATTGGCACCTGGTACTCT \\
NTCP & CAGCTCTGTGTGAACCTGGA & TTCTTCAGGTTCGGGATCAG \\
SREBP-2 & CCTCCCTGATGCCCTTCTCT & GAATCCTGTTTCCATGCTGATG \\
\hline
\end{tabular}

$A B C$, ATP-binding cassette transporter; BSEP, bile salt export pump; CYP7A1, cholesterol $7 \alpha$-hydroxylase; HMG-CoA, hydroxymethylglutaryl-CoA; NTCP, sodium-taurocholate co-transporting polypeptide; SREBP, sterol regulatory element-binding protein. 


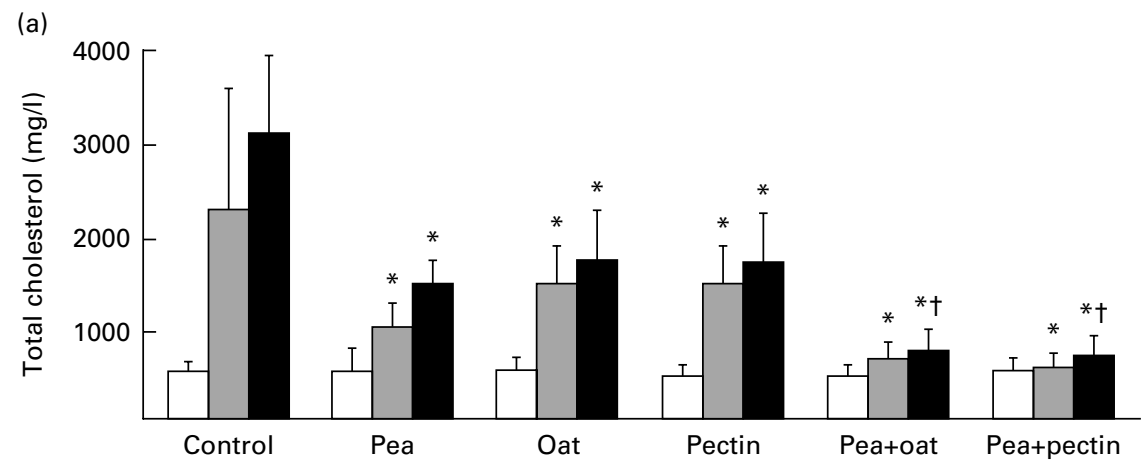

(b)
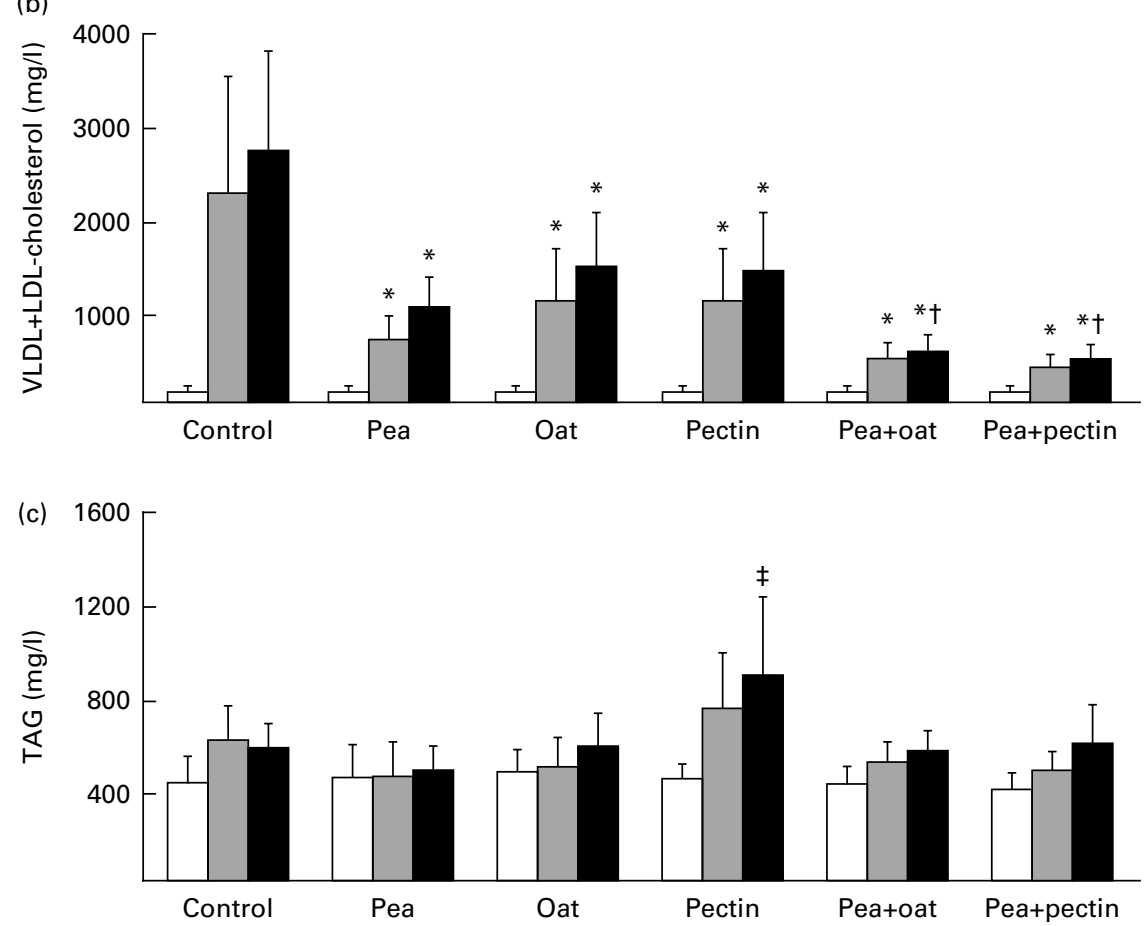

Fig. 1. Plasma concentrations of (a) total cholesterol, (b) VLDL + LDL-cholesterol and (c) TAG in male rats fed, for $28 \mathrm{~d}$, Nath's hypercholesterolaemic diets differing in protein and fibre sources. Plasma lipid analysis was performed before, during (14d) and at the end of the dietary treatment ( $28 \mathrm{~d})$. Values are means, with standard deviations represented by vertical bars $(n 12)$. ${ }^{*}$ Mean values were significantly different from those of the control diet $(P<0.005)$. † Mean values were significantly different from those of the fibre-alone diet $(P<0.005)$. $¥$ Mean value was significantly different from that of the control diet $(P<0.05)$. $\square, 0 \mathrm{~d} ; \square, 14 \mathrm{~d} ; \boldsymbol{\square}, 28 \mathrm{~d}$.

at $28 \mathrm{~d}$ ( -53 and $-54 \%$, respectively, $P<0.001$; Fig. 1(a)). No significant differences among the groups were observed for HDL-cholesterol concentrations ( $P>0 \cdot 05$, data not shown). On the contrary, plasma concentrations of VLDL + LDL-cholesterol in rats fed the diets containing vegetable proteins, fibres or the combinations were markedly lower than those in the animals fed the control diet, at both 14 and $28 \mathrm{~d}$ of treatment, and the two combinations were more effective in lowering plasma cholesterol concentrations when compared with fibres alone (Fig. 1(b)).

No significant variations in TAG concentrations were detected, except for the group fed apple pectin, where a significant increase was observed at $28 \mathrm{~d}$ of dietary treatment (Fig. 1(c)).

Rats fed the diets containing oat fibres, apple pectin or the combinations had a lower cholesterol content in the liver compared with the control rats, whereas no variations were detected between the controls and the pea protein-fed animals (Fig. 2(a)). No changes in hepatic TAG content were instead observed among the groups (Fig. 2(b)).

\section{Effect of the diets on the hepatic MRNA concentration of genes involved in cholesterol metabolism}

In order to examine the possible mechanisms behind the different impacts of the vegetable-containing diets on cholesterolaemia, hepatic gene expression of several key enzymes and transporters involved in cholesterol and bile acid metabolism was evaluated (Table 3).

In the pectin group, hepatic mRNA concentrations of hydroxymethyl-glutaryl-CoA (HMG-COA reductase) and $L D L$ receptor were raised when compared with the control group $(P<0.05)$. No differences among the groups were observed for mRNA levels of sterol regulatory element-binding protein-2 

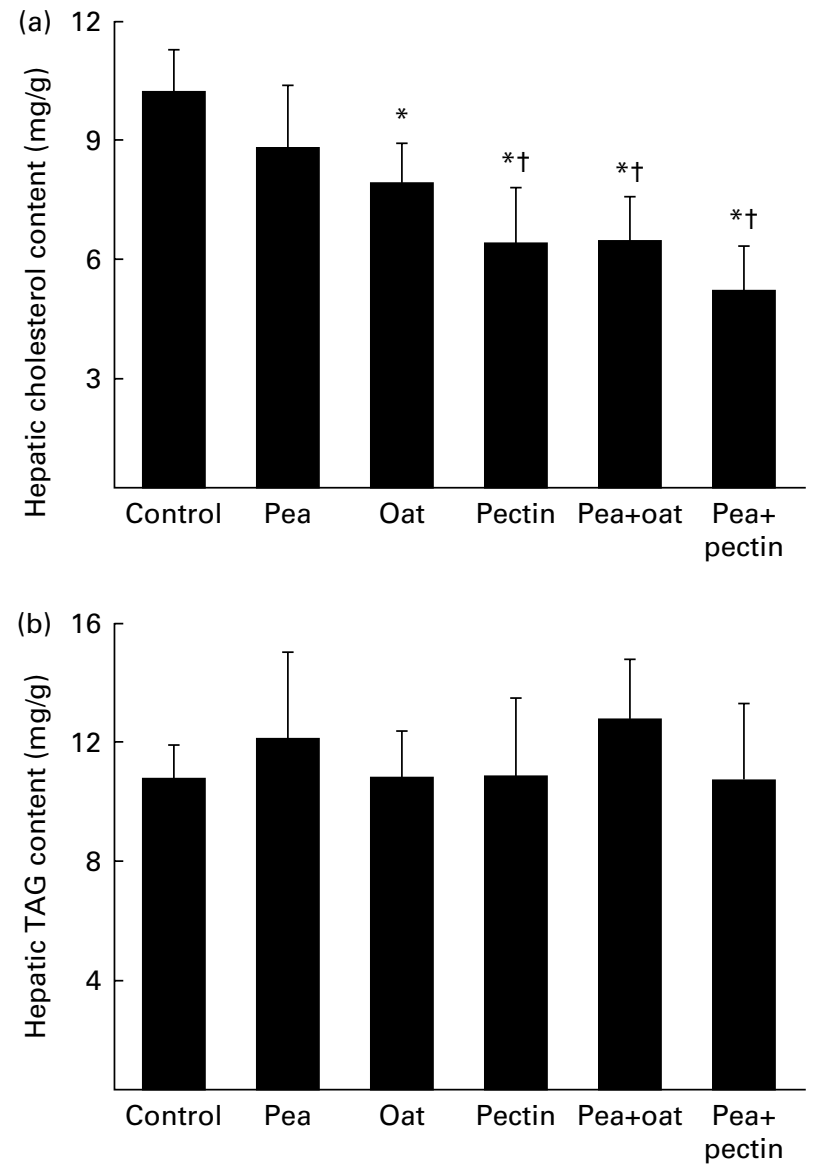

Fig. 2. Liver content of (a) total cholesterol, and (b) TAG in male rats fed, for $28 \mathrm{~d}$, Nath's hypercholesterolaemic diets differing in protein and fibre sources. Data are expressed as $\mathrm{mg}$ lipid/g tissue. Values are means, with standard deviations represented by vertical bars $(n 12) .{ }^{*}$ Mean values were significantly different from those of the control diet $(P<0.005)$. $†$ Mean values were significantly different from those of the pea diet $(P<0.005)$.

(SREBP-2). Rats fed pea proteins had higher hepatic mRNA levels of ATP-binding cassette transporter G5 (ABCG5) and G8 $(A B C G 8)$ than the controls $(P<0.05)$. Moreover, rats fed the diets containing oat fibres or apple pectin, alone or combined with pea proteins, had higher hepatic mRNA concentrations of CYP7A1 when compared with the control rats $(P<0.05)$. All the diets significantly up-regulated liver sodium-taurocholate co-transporting polypeptide (NTCP) mRNA concentrations, but did not show any effect on the hepatic mRNA levels of bile salt export pump (BSEP).

\section{Effect of the diets on hepatic cholesterol $7 \alpha$-hydroxylase protein expression}

The protein expression of hepatic CYP7A1 in the experimental groups is shown in Fig. 3. Rats fed the diets containing apple pectin and the two combinations (pea proteins + oat fibres and pea proteins + apple pectin) showed higher CYP7A1 protein expression compared with the controls $(P<0.05)$. The group fed oat fibres displayed a trend towards higher expression when compared with the controls, but did not reach statistical significance.

\section{Discussion}

In the present study, each dietary treatment containing vegetable proteins and/or soluble fibres substantially lowered plasma cholesterol concentrations, if compared with the control diet containing animal proteins and insoluble fibres. The most effective cholesterol-lowering regimens were those combining pea proteins with oat fibres or apple pectin. Considering the hypocholesterolaemic effect of the dietary treatments containing the single effective ingredients (only pea proteins or only soluble fibres), it appears that the cholesterol reduction obtained with the combination of vegetable proteins and soluble fibres is likely to be due to an additive effect. Although this result can be considered somehow expected on the basis of previous studies testing the efficacy of the so-called portfolio diets ${ }^{(26-28)}$, the possibility of a synergistic effect could not be excluded, based on the supposed mechanisms of action of these bioactive ingredients ${ }^{(5,29)}$. Indeed, the effect of these dietary components on cholesterol metabolism was explored in the present study, through quantitative real-time PCR.

Previous studies in rodents, performed by the present and other research groups, explored the effect of pea proteins on plasma lipids. Pea proteins generally displayed a marked hypocholesterolaemic activity ${ }^{(18,30,31)}$, sometimes associated with a hypotriacylglycerolaemic effect ${ }^{(18,31)}$. The present study confirmed the great efficacy of pea proteins in lowering plasma cholesterol concentrations, but failed in showing any effect on TAG. A possible explanation for the lack of hypotriacylglycerolaemic effect may reside in the very low basal TAG concentrations in rats, associated with the absence of a significant TAG rise in the control group that may have hindered a possible efficacy of pea proteins in modulating plasma TAG concentrations.

Legume proteins are believed to lower plasma cholesterol concentrations, at least in part, by LDL receptor activation ${ }^{(5)}$. In the present study, we did not observe any significant transcriptional activation of $S R E B P-2$ and its target genes, including the $L D L$ receptor, in the group fed pea proteins, but we instead observed a strong activation of $A B C G 5 / G 8$. The ABCG5/G8 transporter promotes the removal of sterols from the body by mediating the transport of sterols, including cholesterol, from intestinal enterocytes into the gut lumen and from hepatocytes into the biliary space ${ }^{(32)}$. The effect of dietary pea proteins on $A B C G 5 / G 8$ has never been explored previously, but a transcriptional activation of this transporter in the liver has been observed in a previous study investigating the effect of a dietary soya protein isolate on cholesterolaemia in rats ${ }^{(33)}$. The present results support this observation and are corroborated by previous findings in rats, indicating an increase of faecal cholesterol excretion by soya proteins $^{(34,35)}$, although this effect is not consistent in clinical studies $^{(36,37)}$. Altogether, these data suggest that $A B C G 5 / G 8$ activation may play a role in the hypocholesterolaemic effect of legume proteins.

In the present study, the soluble fibres tested, i.e. $\beta$-glucan from oats and pectin from apples, both displayed a marked hypocholesterolaemic activity. Dietary soluble fibres are 
Table 3. Relative mRNA concentrations of the hepatic genes involved in the lipid metabolism of rats fed, for $28 \mathrm{~d}$, Nath's hypercholesterolaemic diets, differing in protein and fibre sources§

(Mean values and standard deviations, $n$ 12)

\begin{tabular}{|c|c|c|c|c|c|c|c|c|c|c|c|c|}
\hline & \multicolumn{2}{|c|}{ Control } & \multicolumn{2}{|c|}{ Pea } & \multicolumn{2}{|c|}{ Oat } & \multicolumn{2}{|c|}{ Pectin } & \multicolumn{2}{|c|}{ Pea + oat } & \multicolumn{2}{|c|}{ Pea + pectin } \\
\hline & Mean & SD & Mean & SD & Mean & SD & Mean & SD & Mean & SD & Mean & SD \\
\hline ABCG5 & 1.00 & 0.88 & $2 \cdot 22^{\star}$ & 1.34 & 1.29 & 0.84 & 0.56 & 0.51 & 1.95 & 1.02 & $1 \cdot 18$ & 0.66 \\
\hline$A B C G 8$ & 1.00 & 0.65 & $3.87 \dagger$ & 4.05 & 0.73 & 0.39 & 0.59 & 0.37 & $2 \cdot 83$ & $2 \cdot 21$ & 0.73 & 0.41 \\
\hline$B S E P$ & 1.00 & 0.26 & 0.86 & 0.05 & 0.77 & 0.17 & 0.90 & 0.18 & 0.80 & 0.34 & 1.00 & 0.27 \\
\hline CYP7A1 & 1.00 & 0.46 & 1.47 & 0.65 & $3.08^{*}$ & $2 \cdot 00$ & $2 \cdot 95^{\star}$ & 1.06 & $3.45^{\star}$ & $2 \cdot 10$ & $5 \cdot 33 \ddagger$ & 1.86 \\
\hline HMG-CoA red & 1.00 & 0.24 & 1.08 & 0.34 & 1.43 & 0.61 & $2 \cdot 12 \ddagger$ & 0.46 & 1.28 & 0.55 & $1 \cdot 18$ & 0.38 \\
\hline LDL receptor & 1.00 & 0.52 & 0.97 & 0.25 & $1 \cdot 18$ & 0.23 & $1.76 \ddagger$ & 0.41 & 1.20 & 0.50 & $1 \cdot 16$ & 0.31 \\
\hline NTCP & 1.00 & 0.49 & $1.83^{\star}$ & 0.68 & $1.79^{\star}$ & 0.26 & $2 \cdot 09^{*}$ & 0.57 & $1 \cdot 67^{\star}$ & 0.31 & $2 \cdot 07^{*}$ & 0.42 \\
\hline SREBP-2 & 1.00 & 0.28 & 0.91 & 0.16 & 0.97 & 0.22 & 1.28 & 0.40 & 0.92 & 0.15 & 0.99 & 0.22 \\
\hline
\end{tabular}

$A B C$, ATP-binding cassette transporter; BSEP, bile salt export pump; CYP7A1, cholesterol $7 \alpha$-hydroxylase; HMG-CoA red, hydroxymethyl-glutaryl-CoA reductase; $N T C P$, sodium-taurocholate co-transporting polypeptide; $S R E B P$, sterol regulatory element-binding protein.

${ }^{*}$ Mean values were significantly different from those of the control diet $(P<0.05)$.

$\dagger$ Mean value was significantly different from that of the control, oat, pectin and pea + pectin diets $(P<0.05)$.

$\ddagger$ Mean values were significantly different from those of all the other diets $(P<0.05)$.

$\S$ Values were normalised to the reference gene cyclophilin and are expressed relative to the levels in the control animals set as 1.

believed to alter hepatic cholesterol homeostasis primarily by reducing dietary cholesterol uptake in the intestine and by increasing the faecal loss of bile acids, thus reducing the enterohepatic bile acid pool ${ }^{(38)}$. As a consequence, cholesterol is rapidly catabolised in the hepatocyte to replenish the bile acid pool via the activation of CYP7A1, the rate-limiting enzyme in bile acid synthesis ${ }^{(12)}$. Indeed, in the present study, a significant transcriptional increase of this enzyme was found in rats fed both oat fibres and apple pectin. A significant reduction in hepatic cholesterol content was observed with both soluble fibres, possibly as a consequence of reduced intestinal cholesterol absorption and increased bile acid synthesis. In response to the hepatic cholesterol depletion, a compensatory increase in the expression of HMG-CoA reductase and LDL-receptor may occur $^{(12)}$, the latter contributing to plasma cholesterol lowering. Increased expression of $H M G-C O A$ reductase and LDL-receptor was found in pectin-fed rats, whereas no changes $v$. controls
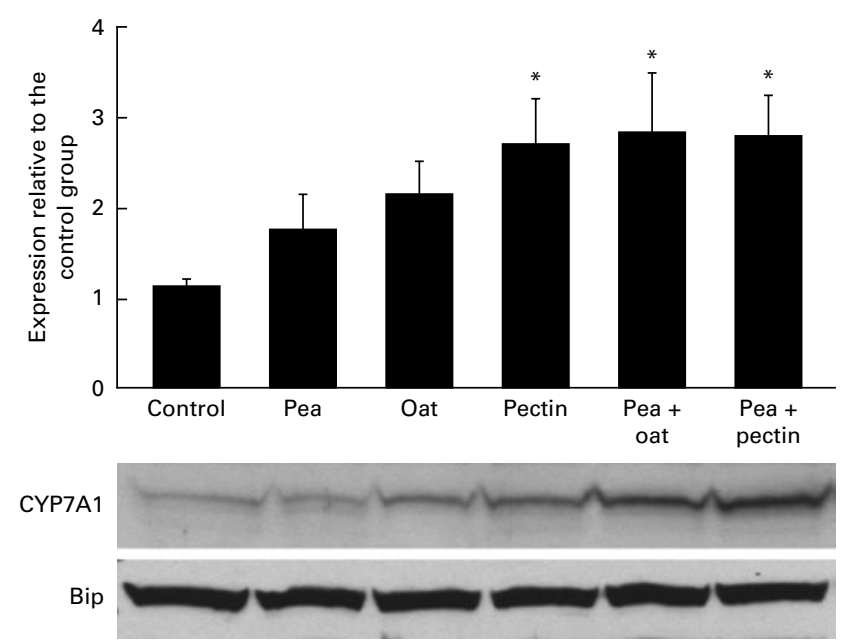

Fig. 3. Expression of cholesterol $7 \alpha$-hydroxylase (CYP7A1) in the rat liver and representative image of CYP7A1 immunoblotting experiments. Microsomal membranes were prepared from liver homogenates and $100 \mu \mathrm{g}$ of proteins were subjected to immunoblotting using a polyclonal antibody directed against CYP7A1. * Mean values were significantly different from those of the control diet $(P<0.005)$. BiP, Ig heavy chain-binding protein. were found for oat fibre-fed rats, suggesting that the hypocholesterolaemic effect of oat fibres may be mostly consequent to reduced intestinal cholesterol absorption. Surprisingly, the dietary treatment with pectin significantly raised TAG plasma concentrations. Dietary treatments with pectin, and generally with soluble fibres, lower or do not modify TAG levels. However, it has been reported that soluble fibre feeding may cause the hepatic secretion of large, TAG-rich $\mathrm{VLDL}^{(39)}$. We may hypothesise that this effect has also occurred in the present study, leading to a plasma TAG rise in pectin-fed rats. In this regard, it should also be noted that bile acid sequestrants, used in the clinic as hypocholesterolaemic drugs, often raised TAG concentrations by increasing VLDL production ${ }^{(40,41)}$.

The combination of soluble fibres and pea proteins led to a further decrease of plasma cholesterol concentrations compared with the single ingredients, which was significant with respect to soluble fibres alone. The transcriptional activation of CYP7A1 observed in rats fed oat fibres or apple pectin was maintained in both treatments combining pea proteins and soluble fibres, and was significantly higher in rats fed pea proteins plus apple pectin $v$. any other dietary regimen. To validate the transcriptional data obtained, Western blotting analysis of CYP7A1 expression was performed. The results were overall in line with the real-time PCR results, suggesting a good correlation between RNA and protein levels. The additional stimulation of CYP7A1 gene transcription by pea proteins plus apple pectin feeding may suggest that this dietary combination could have further increased the bile acid loss mediated by pectin alone, leading to raised bile acid synthesis. Interestingly, the increased transcriptional activation of $A B C G 5 / G 8$ observed after feeding a pea protein-only diet was not maintained for the diets containing both soluble fibres and pea proteins. ABCG5/G8 expression is stimulated by liver X receptor in response to hepatic cholesterol overload to enhance biliary cholesterol secretion ${ }^{(32)}$. The diets containing the combinations of pea proteins and soluble fibres significantly reduced the hepatic cholesterol content $v$. the treatment with pea proteins alone. This hepatic cholesterol reduction 
may have caused the lack of $A B C G 5 / G 8$ transcriptional activation induced by pea protein feeding.

Finally, no dietary regimens affected the expression of BSEP, which mediates the canalicular excretion of bile acids ${ }^{(42)}$. On the contrary, NTCP expression, the transporter that is primarily responsible for the hepatic uptake of bile acids ${ }^{(42)}$, was increased. NTCP expression is increased by agents stimulating the bile acid turnover, such as cholestyramine ${ }^{(43)}$, and it is reduced, similar to CYP7A1, by farnesoid X receptor, in the presence of high bile acid levels ${ }^{(44)}$. Increased cholesterol excretion or reduced bile acid absorption mediated by the dietary regimens could therefore be responsible for the observed effect.

In conclusion, pea proteins, apple pectin or oat fibres are dietary components extremely effective in reducing cholesterolaemia in rats. The combination of these ingredients in the diet results in an additional efficacy with respect to soluble fibres alone, mainly consequent to reduced cholesterol and bile acid absorption. The hypothesis that this type of combinations may be of clinical value is supported by recent data showing a moderate hypocholesterolaemic effect in subjects consuming low amounts of these combined ingredients ${ }^{(45)}$.

\section{Acknowledgements}

The present study was supported by a grant of the European Commission, CRAFT Project Bioprofibre (COOP-CT-2006032075). We are very grateful to Dr David Russell for his helpful suggestions on liver microsome preparation and for providing the anti-CYP7A1 antibody. The authors' contributions were as follows: C. P., M. M., C. R. S. and G. C. designed the study; C. P., M. B., E. R., M. M., E. D. and S. M. performed the study; C. P., M. M. and G. C. performed the data analyses; C. P., C. R. S. and G. C. wrote the manuscript; G. C. had primary responsibility for the study, data acquisition, interpretation and final content of the manuscript. The authors declare no conflict of interest.

\section{References}

1. De Backer G, Ambrosioni E, Borch-Johnsen K, et al. (2003) European guidelines on cardiovascular disease and prevention in clinical practice. Atherosclerosis 171, 145-155.

2. Stampfer MJ, Hu FB, Manson JE, et al. (2000) Primary prevention of coronary heart disease in women through diet and lifestyle. $N$ Engl J Med 343, 16-22.

3. Kris-Etherton PM, Etherton TD, Carlson J, et al. (2002) Recent discoveries in inclusive food-based approaches and dietary patterns for reduction in risk for cardiovascular disease. Curr Opin Lipidol 13, 397-407.

4. Hill AM, Fleming JA \& Kris-Etherton PM (2009) The role of diet and nutritional supplements in preventing and treating cardiovascular disease. Curr Opin Cardiol 24, 433-441.

5. Sirtori CR, Galli C, Anderson JW, et al. (2009) Functional foods for dyslipidaemia and cardiovascular risk prevention. Nutr Res Rev 22, 244-261.

6. Huang J, Frohlich J \& Ignaszewski AP (2011) The impact of dietary changes and dietary supplements on lipid profile. Can J Cardiol 27, 488-505.

7. Anderson JW (2000) Dietary fiber prevents carbohydrateinduced hypertriglyceridemia. Curr Atberoscler Rep 2 536-541.
8. Erkkila AT \& Lichtenstein AH (2006) Fiber and cardiovascular disease risk: how strong is the evidence? J Cardiovasc Nurs 21, 3-8.

9. Harland JI (2012) Food combinations for cholesterol lowering. Nutr Res Rev 25, 249-266.

10. EFSA Panel on Dietetic Products; Nutrition and Allergies (NDA) (2010) Scientific opinion on the substantiation of a health claim related to oat $\beta$-glucan and lowering blood cholesterol and reduced risk of (coronary) heart disease pursuant to Article 14 of Regulation (EC) no. 1924/2006. EFSA J 8, 1885 .

11. EFSA Panel on Dietetic Products; Nutrition and Allergies (NDA) (2011) Scientific opinion on the substantiation of a health claim related to barley $\beta$-glucans and lowering of blood cholesterol and reduced risk of (coronary) heart disease pursuant to Article 14 of Regulation (EC) no. 1924/ 20061. EFSA J 9, 2471.

12. Gunness P \& Gidley MJ (2010) Mechanisms underlying the cholesterol-lowering properties of soluble dietary fibre polysaccharides. Food Funct 1, 149-155.

13. Kim DN, Lee KT, Reiner JM, et al. (1980) Increased steroid excretion in swine fed high-fat, high-cholesterol diet with soy protein. Exp Mol Pathol 33, 25-35.

14. Terpstra AH, Woodward CJ, West CE, et al. (1982) A longitudinal cross-over study of serum cholesterol and lipoproteins in rabbits fed on semi-purified diets containing either casein or soya-bean protein. Br J Nutr 47, 213-221.

15. Bakhit RM, Klein BP, Essex-Sorlie D, et al. (1994) Intake of $25 \mathrm{~g}$ of soybean protein with or without soybean fiber alters plasma lipids in men with elevated cholesterol concentrations. J Nutr 124, 213-222.

16. Sirtori CR, Lovati MR, Manzoni C, et al. (1995) Soy and cholesterol reduction: clinical experience. J Nutr $\mathbf{1 2 5}$, 598S-605S.

17. Sirtori CR, Lovati MR, Manzoni C, et al. (2004) Proteins of white lupin seed, a naturally isoflavone-poor legume, reduce cholesterolemia in rats and increase LDL receptor activity in HepG2 cells. J Nutr 134, 18-23.

18. Rigamonti E, Parolini C, Marchesi M, et al. (2010) Hypolipidemic effect of dietary pea proteins: impact on genes regulating hepatic lipid metabolism. Mol Nutr Food Res 54, Suppl. 1, S24-S30.

19. Bazzano LA, Thompson AM, Tees MT, et al. (2011) Non-soy legume consumption lowers cholesterol levels: a meta-analysis of randomized controlled trials. Nutr Metab Cardiovasc Dis 21, 94-103.

20. Schultz JR, Gong EL, McCall MR, et al. (1992) Expression of human apolipoprotein A-II and its effect on high density lipoproteins in transgenic mice. $J$ Biol Chem 267, 21630-21636.

21. Chiesa G, Parolini C, Canavesi M, et al. (1998) Human apolipoproteins A-I and A-II in cell cholesterol efflux: studies with transgenic mice. Arterioscler Thromb Vasc Biol 18, 1417-1423.

22. Parolini C, Chiesa G, Zhu Y, et al. (2003) Targeted replacement of mouse apolipoprotein A-I with human ApoA-I or the mutant ApoA-IMilano. Evidence of apoA-IM impaired hepatic secretion. J Biol Chem 278, 4740-4746.

23. Parolini C, Chiesa G, Gong E, et al. (2005) Apolipoprotein A-I and the molecular variant apoA-I (Milano): evaluation of the antiatherogenic effects in knock-in mouse model. Atherosclerosis 183, 222-229.

24. Folch J, Lees M \& Sloane Stanley GH (1957) A simple method for the isolation and purification of total lipides from animal tissues. J Biol Chem 226, 497-509. 
25. Li-Hawkins J, Lund EG, Turley SD, et al. (2000) Disruption of the oxysterol 7alpha-hydroxylase gene in mice. J Biol Chem 275, 16536-16542.

26. Aquilani R, Tramarin R, Pedretti RF, et al. (1999) Despite good compliance, very low fat diet alone does not achieve recommended cholesterol goals in outpatients with coronary heart disease. Eur Heart J 20, 1020-1029.

27. Lukaczer D, Liska DJ, Lerman RH, et al. (2006) Effect of a low glycemic index diet with soy protein and phytosterols on CVD risk factors in postmenopausal women. Nutrition 22, 104-113.

28. Jenkins DJ, Kendall CW, Faulkner DA, et al. (2006) Assessment of the longer-term effects of a dietary portfolio of cholesterol-lowering foods in hypercholesterolemia. $\mathrm{Am} \mathrm{J}$ Clin Nutr 83, 582-591.

29. Nijjar PS, Burke FM, Bloesch A, et al. (2010) Role of dietary supplements in lowering low-density lipoprotein cholesterol: a review. J Clin Lipidol 4, 248-258.

30. Jacques H, Deshaies Y \& Savoie L (1986) Relationship between dietary proteins, their in vitro digestion products, and serum cholesterol in rats. Atherosclerosis 61, 89-98.

31. Lasekan JB, Gueth L \& Khan S (1995) Influence of dietary golden pea proteins versus casein on plasma and hepatic lipids in rats. Nutr Res 15, 71-84.

32. Sabeva NS, Liu J \& Graf GA (2009) The ABCG5 ABCG8 sterol transporter and phytosterols: implications for cardiometabolic disease. Curr Opin Endocrinol Diabetes Obes 16, 172-177.

33. Ikeda I, Kudo M, Hamada T, et al. (2009) Dietary soy protein isolate and its undigested high molecular fraction upregulate hepatic ATP-binding cassette transporter G5 and ATP-binding cassette transporter G8 mRNA and increase biliary secretion of cholesterol in rats. J Nutr Sci Vitaminol (Tokyo) 55, 252-256.

34. Nagata Y, Tanaka K \& Sugano M (1981) Further studies on the hypocholesterolaemic effect of soya-bean protein in rats. Br J Nutr 45, 233-241.
35. Sugano M, Goto S, Yamada Y, et al. (1990) Cholesterollowering activity of various undigested fractions of soybean protein in rats. J Nutr 120, 977-985.

36. Fumagalli R, Soleri L, Farina R, et al. (1982) Fecal cholesterol excretion studies in type II hypercholesterolemic patients treated with the soybean protein diet. Atherosclerosis 43, $341-353$.

37. Maki KC, Butteiger DN, Rains TM, et al. (2010) Effects of soy protein on lipoprotein lipids and fecal bile acid excretion in men and women with moderate hypercholesterolemia. J Clin Lipidol 4, 531-542.

38. Rideout TC, Harding SV, Jones PJ, et al. (2008) Guar gum and similar soluble fibers in the regulation of cholesterol metabolism: current understandings and future research priorities. Vasc Health Risk Manag 4, 1023-1033.

39. Fernandez ML (2001) Soluble fiber and nondigestible carbohydrate effects on plasma lipids and cardiovascular risk. Curr Opin Lipidol 12, 35-40.

40. Einarsson K, Ericsson S, Ewerth S, et al. (1991) Bile acid sequestrants: mechanisms of action on bile acid and cholesterol metabolism. Eur J Clin Pharmacol 40, Suppl. 1, S53-S58.

41. Aldridge MA \& Ito MK (2001) Colesevelam hydrochloride: a novel bile acid-binding resin. Ann Pharmacother 35, 898-907.

42. Anwer MS (2004) Cellular regulation of hepatic bile acid transport in health and cholestasis. Hepatology 39, 581-590.

43. Cheng X, Buckley D \& Klaassen CD (2007) Regulation of hepatic bile acid transporters Ntcp and Bsep expression. Biochem Pharmacol 74, 1665-1676.

44. Teodoro JS, Rolo AP \& Palmeira CM (2011) Hepatic FXR: key regulator of whole-body energy metabolism. Trends Endocrinol Metab 22, 458-466.

45. Sirtori CR, Triolo M, Bosisio R, et al. (2012) Hypocholesterolaemic effects of lupin protein and pea protein/fibre combinations in moderately hypercholesterolaemic individuals. $\mathrm{Br}$ J Nutr 107, 1176-1183. 